\title{
CORRESPONDENCE Combating racism: the role of the pediatrician
}

Pediatric Research (2021) 90:708-710; https://doi.org/10.1038/s41390020-01345-x

George Floyd. Philando Castile. Sandra Bland. Ahmaud Arbery. Alton Sterling. Breonna Taylor. Eric Garner. Michael Brown. All of these individuals, as well as those involved in their deaths, were once children. They were impressionable, watching and learning from everyone around them. They all started out with the same innocence and potential with which every child is born. Yet somewhere along the way, the innocence was lost, and tragic circumstances intervened, resulting in the deaths that have brought renewed attention to the deeply engrained racism in our country. As we move forward with newfound momentum to make long-lasting change, we as pediatricians must address the role we have in fighting racism on an individual, as well as a systemic, level.

When it comes to individual racism, there is no population more impressionable and affected by their surroundings than our nation's children. Anyone who spends time with children knows that they are constantly absorbing all that is said and done around them. Even when we may prefer that they remain ignorant, they are ongoing witnesses to how we treat one another. A child is not born racist, but rather they learn from any adult or child around them from a very early age. As we embark on a journey of selfreflection and self-improvement, we must acknowledge that one of the most meaningful approaches we can take to combating racism as academic pediatricians is to encourage parents to raise anti-racist children in our clinical roles and to promote educational and research agendas that inform this mission. To do this, we must take responsibility for the racist culture in which children are raised and affirm that racism is an issue that impacts children at each stage of development and can be fought from the earliest moments in childhood.

The health disparities related to racism are rampant and well documented, especially in children and their mothers. Black children are impacted by racism before they are even born. There is ongoing evidence suggesting that maternally experienced racism and the accompanying stress may be related to increased preterm birth in Black mothers. ${ }^{1}$ The compounding stress that Black mothers experience secondary to racism is also associated with disparities in early childhood growth and development. ${ }^{2}$

A child's understanding of race is influenced by his or her experiences throughout development. After birth, babies look equally at faces of all races. However, by the age of 3 months, babies start to show a preference for faces that match the race of their caregivers. ${ }^{3}$ As early as age 3 years, children have been shown to start demonstrating anti-Black and pro-White biases when choosing playmates. ${ }^{4}$ Then, when children reach kindergarten age, Black and Hispanic children show no preference between their own racial group and White children, while White children demonstrate preference toward their own racial peer group. ${ }^{5-7}$

These experiences lead to deeply internalized attitudes about race, even in young children. This concept was first demonstrated in the 1940s with the well-known "doll tests." Dr. Kenneth and Dr. Mamie Clark were psychologists who showed that, when Black and White children were presented with dolls of different skin colors, children of both races preferred the White doll. Both Black and White children attributed all the possible positive characteristics to the White doll over the Black doll. Additionally, when asked to identify with one of the dolls, Dr. Kenneth Clark states that the Black children became "emotionally upset at having to identify with the doll that they had rejected." Some children reacted so strongly that they stormed out of the room. ${ }^{8,9}$

The perception of racial differences becomes more troubling as children age. In 2014, a study out of the Georgetown Law Center on Poverty and Inequality showed that beginning at the age of 10 years, Black boys are more likely to be perceived as older, to be viewed as guilty of suspected crimes, and to face police violence if accused of a crime compared to White boys of the same age. ${ }^{10} \mathrm{~A}$ similar study in 2017 showed that, when compared to White girls, Black girls are commonly presumed to be older and more independent and to require less nurturing, less support, less comfort, and less protection. ${ }^{10}$ School-aged Black children are often subject to harsher discipline and are more frequently expelled, and Black adolescents who experience discrimination have more negative psychological outcomes than their White peers. ${ }^{11,12}$ Black adolescents' and pre-adolescents' perceptions of racism are associated with mental health concerns, including depressive symptoms, low self-esteem, anxiety, anger, and conduct problems. ${ }^{13}$ The cycle of racism endured by Black children affects their development from conception to adolescence.

To break these trends, we as pediatricians must encourage parents and other family members to speak with their children about racism early and often. This task can be daunting, so we must be armed with appropriate anticipatory guidance, resources, and data to back up these recommendations. Studies have shown that racial biases can be diminished by speaking directly with children positively about inter-racial friendships. ${ }^{14}$ Furthermore, inter-racial friendships and group contact have resulted in decreased race-based exclusion for school-aged children. ${ }^{15}$ Minority parents have reported that they feel that racial socialization in early childhood is crucial for school readiness and could decrease race-based gaps in school achievement. ${ }^{16}$ Having these conversations early with children can also prevent later shame when inevitably learning about racism for White children, as well as trauma related to the shock of learning about racism for Black children. ${ }^{17}$ We must hold ourselves accountable for raising a generation of more tolerant citizens with healthy, positive views of diversity.

Individually, we pediatricians must continue to devote time and effort to address our own biases and progress on our own antiracist journeys. Despite progress in treating and preventing many diseases overall, health disparities continue to exist with Black individuals bearing higher rates of diabetes, obesity, asthma, and hypertension than their white counterparts. ${ }^{18-21}$ Even providers who are well intentioned may easily slip into stereotyping racial/ ethnic minority members. ${ }^{22}$ We must acknowledge that we as health care providers contribute to health disparities.

Significant changes must also occur in our medical education system. Medical education has not become more hospitable for Black trainees, who were blatantly discriminated against and barred entry into many medical professional organizations until

Received: 6 August 2020 Revised: 8 December 2020 Accepted: 9 December 2020

Published online: 19 January 2021 
relatively recently. Black trainees continue to face challenges with medical school matriculation and retention, with Black male medical student matriculation rates failing to increase between 1978 and 2014. ${ }^{23}$ The development and support of pipeline programs to encourage Black students to pursue a career in medicine are vital. In order for these pipeline programs to succeed, academic medical centers must focus on development of partnerships with underserved communities, demonstration of a strong commitment to increasing racial and ethnic minorities in the health professions, and creation of sustainable funding mechanisms to support these programs. ${ }^{24}$ Once Black students arrive in medical school, they often bear the burden of having to educate others about racism. This experience has been described as the "conscripted curriculum," which forces students of color to share their social experiences with race in the small group setting leading to a disproportionate burden of exhausting and unrewarded emotional labor for Black students as compared to their White peers. ${ }^{25}$ Medical education has a responsibility to not only ensure that future physicians are culturally sensitive in their practice but also to review what and how we are taught about race in the context of medicine.

At a clinical level, we can examine the screenings that we perform, the materials that we share, the language that we use, and we can ask ourselves if we are providing the best care for each of the families we serve. Providing specific anticipatory guidance to families around anti-racist practices is a crucial first step. As we guide caretakers regarding behavior and safety, we should also be preparing them to have discussions regarding race and affirm that it is never too early to begin these conversations. We should encourage families to weave themes of diversity into conversation with their children, to foster cultural pride however it may apply to them, to seek books and other media that reinforce a positive view of embracing racial diversity, and to consider how to discuss our differences in a positive way as children make their own comments regarding race. These conversations have been proven to be vital, as one study found that strong parental endorsement of cultural pride reinforcement messages was predictive of significantly lower anxiety scores in African American children. ${ }^{26}$ We can also work toward creating an environment in clinics that reinforces these values by providing culturally sensitive materials and handing out books that embrace diversity with proper representation of all people. Finally, we must acknowledge that race-related disparities in the medical workforce negatively affect our patients, and we must embrace diversity as a strength in any health care environment. It is our responsibility to discern how we can provide more equitable care to individuals and influence our medical infrastructure to create systemic change that reverses race-related health inequities.

On a larger scale, we as a community of pediatricians and researchers must take responsibility for the message communicated by where we invest our time and money in research. We must work toward more precise ways to measure how racism infiltrates medical practice. We must be more diligent in our efforts toward race-related disparity research, and we must be invested in issues that affect our Black patients. Our agenda as it relates to child health must address all children and must recognize that Black children desperately need this investment.

Additionally, we must be responsible for understanding how medical research can contribute to distortion of truth and misunderstanding of race. One method to address the root causes of racism in research is the application of Critical Race Theory, a framework that focuses on anti-racist tenets, modes of knowledge production, and strategies that target the subtle and systemic ways racism permeates scholarly work. ${ }^{27}$ Critical Race Theory can be applied to health research through the use of an anti-racism lexicon that facilitates health equity discourse and the application of the Public Health Critical Race Praxis (PHCRP) ${ }^{28}$ As described by Ford, the PHCRP process begins with researchers analyzing the influence of racial context on the study and then sequentially applying four areas of focus: understanding and addressing issues of contemporary race relations, knowledge production, conceptualization and measurement, and action. We encourage researchers to learn about Critical Race Theory, embrace the lexicon, and apply PHCRP to their research practices. In addition, pediatric research must persist in illuminating and highlighting paths forward in addressing health disparities. Potential areas for focus include interventions to address pediatric health disparities; studies that apply concepts of diversity science, intersectionality of social identities, implicit bias, and cultural humility to understand and reduce health disparities; and studies addressing the role of diversity and cultural humility in medical education. ${ }^{29}$ Emphasis on understanding and mitigating disparities in the current coronavirus disease 2019 pandemic, as well as any future emerging public health threats, must also be at the forefront of our research agenda.

No matter where each of us may start on this journey, the important thing is that we must begin. We must do the challenging work of examining our own biases and committing to making critical changes in our personal and professional lives. As beautifully stated by author ljeoma Oluo, "The beauty of anti-racism is that you don't have to pretend to be free of racism to be anti-racist. Antiracism is the commitment to fight racism wherever you find it, including in yourself. And it's the only way forward." It is our duty as a pediatric community to be a part of that way forward.

\section{ADDITIONAL INFORMATION}

Competing interests: The authors declare no competing interests.

Patient consent: Patient consent was not required for this manuscript.

Publisher's note Springer Nature remains neutral with regard to jurisdictional claims in published maps and institutional affiliations.

Andrea J. Matthew ${ }^{1,2,3}$, Marie A. Clark ${ }^{1,2,3}$ and Lolita M. McDavid ${ }^{1,2,3}$ ${ }^{1}$ Pediatric Residency Program, University Hospitals Cleveland Medical Center, Rainbow Babies and Children's Hospital, Cleveland, $\mathrm{OH}, \mathrm{USA}$; ${ }^{2}$ Department of Developmental-Behavioral Pediatrics and Psychology, University Hospitals Cleveland Medical Center, Rainbow Babies and Children's Hospital, Cleveland, $\mathrm{OH}$, USA and ${ }^{3}$ Department of Child Advocacy and Protection, University Hospitals Cleveland Medical Center, Rainbow Babies and Children's Hospital, Cleveland,

$\mathrm{OH}$, USA

Correspondence: Andrea J. Matthew (andrea.matthew@uhhospitals.org)

\section{REFERENCES}

1. Kramer, M. R. \& Hogue, C. R. What causes racial disparities in very preterm birth? A biosocial perspective. Epidemiol. Rev. 31, 84-98 (2009).

2. Kelly, Y., Becares, L. \& Nazroo, J. Associations between maternal experiences of racism and early child health and development: findings from the UK Millennium Cohort Study. J. Epidemiol. Community Health 67, 35-41 (2013).

3. Kelly, D. J. et al. Three-month-olds, but not newborns, prefer own-race faces. Dev. Sci. 8, F31-F36 (2005).

4. Katz, P. A., \& Kofkin, J. A. in Developmental Psychopathology: Perspectives on Adjustment, Risk, and Disorder (eds Luthar, S. S. \& Burack, J. A.) 51-74 (Cambridge University Press, New York, NY, 1997).

5. Baron, A. S. \& Banaji, M. R. The development of implicit attitudes: evidence of race evaluations from ages 6, 10 \& adulthood. Psychol. Sci. 17, 53-58 (2006).

6. Dunham, Y. et al. Children and social groups: a developmental analysis of implicit consistency in Hispanics Americans. Self Identity 6, 238-255 (2007).

7. Dunham, Y., Baron, A. S. \& Banaji, M. R. The development of implicit intergroup cognition. Trends Cogn. Sci. 12, 248-253 (2008).

8. Beschloss, M. How an experiment with dolls helped lead to school integration The New York Times. http://www.nytimes.com/2014/05/07/upshot/how-anexperiment-with-dolls-helped-lead-to-school-integration.html?smid=em-share (2014). 
9. Clark, K. \& Clark, M. The development of consciousness of self and the emergence of racial identification in negro preschool children. J. Soc. Psychol. 10, 591-599 (1939).

10. Epstein, R., Blake, J. J. \& González, T. Girlhood Interrupted: The Erasure of Black Girls' Childhood (Georgetown Law Center on Poverty and Inequality, Washington, DC, 2017).

11. Skiba, R. J. et al. Race is not neutral: a national investigation of African American and Latino disproportionality in school discipline. Sch. Psychol. Rev. 40, 85-107 (2011).

12. Trent, M., Dooley, D. G. \& Dougé, J. The impact of racism on child and adolescent health. Pediatrics 144, e20191765 (2019).

13. Pachter, L. M. \& Coll, C. G. Racism and child health: a review of the literature and future directions. J. Dev. Behav. Pediatr. 30, 255-263 (2009).

14. Bronson, P. \& Merryman, A. Even babies discriminate: a nurtureshock excerpt. Newsweek. http://www.newsweek.com/even-babies-discriminate-nurtureshockexcerpt-79233 (2009).

15. Crystal, D. S., Killen, M. \& Ruck, M. It is who you know that counts: intergroup contact and judgments about race-based exclusion. Br. J. Dev. Psychol. 26, 51-70 (2008).

16. Anderson, A. T. et al. Minority parents' perspectives on racial socialization and school readiness in the early childhood period. Acad. Pediatr. 15, 405-411 (2015).

17. The Conscious Kid. How to talk to kids about race. https://www.theconsciouskid. org/how-to-talk-to-kids-about-race (2020).

18. National Center for Health Statistics. Health, United States 2018. https://www.cdc. gov/nchs/data/hus/hus18.pdf\#Highlights (2018).

19. National Center for Health Statistics. NCHS data on racial and ethnic disparities. NCHS Fact Sheet March 2019. https://www.cdc.gov/nchs/data/ factsheets/factsheet_disparities.htm (2020).
20. Centers for Disease Control and Prevention. Health of Black or African American non-Hispanic population. https://www.cdc.gov/nchs/fastats/black-health.htm (2020).

21. U.S. Department of Health and Human Services Office of Minority Health. Obesity and African Americans. https://minorityhealth.hhs.gov/omh/browse. aspx? $|v|=4 \& \mid v l i d=25$ (2020).

22. Burgess, D. J., Fu, S. S. \& Van Ryn, M. Why do providers contribute to disparities and what can be done about it? J. Gen. Intern. Med. 19, 1154-1159 (2004).

23. Stowers, J. A., Desrosiers, S., Zeleke, K., Bakare, O., \& Seifi, A. The life of a Black medical trainee in the United States: past, present, future. J. Natl Med. Assoc. https://doi.org/10.1016/j.jnma.2020.07.004 (2020).

24. Smith, S. G., Nsiah-Kumi, P. A., Jones, P. R. \& Pamies, R. J. Pipeline programs in the health professions, part 1: preserving diversity and reducing health disparities. $J$. Natl Med. Assoc. 101, 836-840 (2009).

25. Olsen, L. D. The conscripted curriculum and the reproduction of racial inequalities in contemporary US medical education. J. Health Soc. Behav. 60, 55-68 (2019).

26. Bannon, W. M., McKay, M. M., Chacko, A., Rodriguez, J. A. \& Cavaleri, M. Cultural pride reinforcement as a dimension of racial socialization protective of urban African American child anxiety. Fam. Soc. J. Contemp. Hum. Serv. 90, 79-86 (2009).

27. Crenshaw, K., Gotanda, N., Peller, G. \& Thomas K. (eds) Critical Race Theory: The Key Writings that Formed the Movement (New Press, New York, NY, 1995).

28. Ford, C. L. \& Airhihenbuwa, C. O. Commentary: just what is critical race theory and what's it doing in a progressive field like public health? Ethnicity Dis. 28(Suppl 1), 223 (2018).

29. Valrie, C., Thurston, I. \& Santos, M. Introduction to the special issue: addressing health disparities in pediatric psychology. J. Pediatr. Psychol. 45, 833-838 (2020). 